\title{
María Dolores Mateos Dorado \\ In memoriam
}

Nacida en Salamanca en 1942, la profesora Mateos se incorporó al departamento de Historia Moderna de la Universidad de Oviedo en 1968. En 1983 ingresa en el equipo de investigación del Centro de Estudios del Siglo XVIII, formando parte del mismo hasta su jubilación en 2012. En todos estos años, su colaboración en las variadas tareas del Centro - poco tiempo después convertido en Instituto universitario- fueron múltiples, y en todas ellas puso conocimientos y entusiasmo a partes iguales: cursos de verano en las localidades de Llanes, Navia y Gijón; ciclos de conferencias, mesas redondas, presentaciones de libros, participación en las publicaciones del Instituto y otras muchas actividades siempre relacionadas con el mundo de la Ilustración española y las figuras más relevantes del período en Asturias (Campillo, Feijoo, Campomanes o Jovellanos), así como en la autoría de trabajos de investigación (sobre los economistas y hacendistas asturianos del siglo; el gobierno y la administración en el Principado; el panorama cultural y la universidad de Oviedo; el catastro de Ensenada; la nobleza asturiana; los proyectos e iniciativas del Marqués de Sargadelos, y otros trabajos en los que dejó huella de su rigor intelectual y del amplio conocimiento que poseía sobre nuestro siglo.

Pero, además de su labor investigadora, la profesora Mateos tuvo una especial dedicación a la docencia universitaria, alentando y estimulando vocaciones en las muchas generaciones de estudiantes que pasaron por sus aulas. Excelente comunicadora, no se limitaba a explicar y conducir el programa correspondiente de la asignatura, sino que solía enriquecer sus explicaciones con alusiones frecuentes al cine, el teatro o la literatura. Sus alumnos se habrán aprovechado del caudal de experiencia docente y de su amor por la cultura, ya no solo de los períodos modernos de aquella España, sino de los contextos sociales, religiosos o políticos sobre los que descansaban los hechos que constituían el gran relato de la historia.

El Instituto Feijoo de Estudios del Siglo XVIII quiere, en estas breves y apresuradas líneas, rendir tributo de agradecimiento a quien nos dio tanto durante todos estos años de colaboración y amistad. Descanse en paz.

Álvaro Ruiz de la PeÑa Solar 